\title{
Changes in Body Temperature in Incomplete Spinal Cord Injury by Digital Infrared Thermographic Imaging
}

\author{
Yun-Gyu Song, $\mathrm{MD}^{1}$, Yu Hui Won, $\mathrm{MD}^{1,2}$, Sung-Hee Park, $\mathrm{MD}, \mathrm{PhD}^{1,2}$, \\ Myoung-Hwan Ko, MD, $\mathrm{PhD}^{1,2}$, Jeong-Hwan Seo, $\mathrm{MD}, \mathrm{PhD}^{1,2}$
}

\begin{abstract}
${ }^{1}$ Department of Physical Medicine and Rehabilitation, Chonbuk National University Medical School and Chonbuk National University Hospital, Jeonju; ${ }^{2}$ Research Institute of Clinical Medicine of Chonbuk National University-Biomedical Research Institute of Chonbuk National University Hospital, Jeonju, Korea
\end{abstract}

Objective To investigate changes in the core temperature and body surface temperature in patients with incomplete spinal cord injuries (SCI). In incomplete SCI, the temperature change is difficult to see compared with complete spinal cord injuries. The goal of this study was to better understand thermal regulation in patients with incomplete SCI.

Methods Fifty-six SCI patients were enrolled, and the control group consisted of 20 healthy persons. The spinal cord injuries were classified according to International Standards for Neurological Classification of Spinal Cord Injury. The patients were classified into two groups: upper (neurological injury level T6 or above) and lower (neurological injury level T7 or below) SCIs. Body core temperature was measured using an oral thermometer, and body surface temperature was measured using digital infrared thermographic imaging.

Results Twenty-nine patients had upper spinal cord injuries, 27 patients had lower SCIs, and 20 persons served as the normal healthy persons. Comparing the skin temperatures of the three groups, the temperatures at the lower abdomen, anterior thigh and anterior tibia in the patients with upper SCIs were lower than those of the normal healthy persons and the patients with lower SCIs. No significant temperature differences were observed between the normal healthy persons and the patients with lower SCIs.

Conclusion In our study, we found thermal dysregulation in patients with incomplete SCI. In particular, body surface temperature regulation was worse in upper SCIs than in lower injuries. Moreover, cord injury severity affected body surface temperature regulation in SCI patients.

Keywords Spinal cord injuries, Body temperature regulation, Body temperature, Skin temperature, Thermography

Received April 6, 2015; Accepted May 20, 2015

Corresponding author: Jeong-Hwan Seo

Department of Physical Medicine and Rehabilitation, Chonbuk National University Medical School, 20 Geonji-ro, Deokjin-gu, Jeonju 54907, Korea Tel: +82-63-250-1797, Fax: +82-10-254-4145, E-mail: vivaseo@jbnu.ac.kr

@ This is an open-access article distributed under the terms of the Creative Commons Attribution Non-Commercial License (http://creativecommons.org/ licenses/by-nc/4.0) which permits unrestricted noncommercial use, distribution, and reproduction in any medium, provided the original work is properly cited. Copyright () 2015 by Korean Academy of Rehabilitation Medicine 


\section{INTRODUCTION}

Autonomic dysfunction accompanied by spinal cord injury (SCI) appears in the form of diverse symptoms such as neurogenic shock, arrhythmia, orthostatic hypotension, autonomic dysreflexia, and thermoregulatory dysfunction [1]. Because autonomic dysfunction might threaten life in the early stage of SCI, it needs to be evaluated accurately. Temperature, one of the evaluation indices of autonomic dysfunction, maintains homeostasis against external environment changes and is relatively easy to measure. Thus, temperature can be used as a useful tool for evaluating autonomic nervous system functioning in the early stage of spinal cord injury. Body surface temperature is also known to be regulated by the autonomic nervous system and to have complex interactions with the physical conditions of the surrounding environment, skin fat and dermis thickness, and internal heat conduction and convection [2,3]. Regarding body temperature maintenance, it has been reported that there is a complex interaction between core temperature receptors and peripheral skin temperature receptors [4]. Therefore, in assessing thermoregulatory function in SCI patients, it would be helpful to evaluate not only core temperature but also body surface temperature at the same time. Recently, digital infrared thermographic imaging (DITI) has been used widely to measure body surface temperature. DITI can detect infrared radiation emitted from the body surface for digitization and visualization $[2,5,6]$, and the sympathetic nervous system can be quantitatively evaluated in a relatively easy and quick manner.

In the previous studies on changes in core temperature and body surface temperature of SCI patients, these patients were reported to show declines in core temperature and trunk temperature depending on the level of injury. Most studies have investigated complete SCI, and as such, there are insufficient studies about patients with incomplete SCI [4,7-12]. In these patients, the degree of autonomic nervous system dysfunction is not severe compared with patients with complete SCI, which might make it difficult to accurately evaluate the dysfunction $[1,13]$. This study aims to measure core temperature and body surface temperature in normal healthy persons and in patients with incomplete SCI for comparative analysis by location and duration of injury and severity. This is intended to help evaluate thermoregulatory dysfunction in incomplete SCI patients, which has not been studied sufficiently to date.

\section{MATERIALS AND METHODS}

\section{Subject}

This study enrolled SCI patients with body mass index (BMI) values of $22.0-25.0 \mathrm{~kg} / \mathrm{m}^{2}$ who had been hospitalized in the department of rehabilitation medicine of our hospital from January 1, 2014 to December 31, 2014. Among 64 SCI patients, 8 were excluded with autonomic function disorder, peripheral vascular disorder, peripheral nerve disorder, muscular skeletal disease, and skin lesion. Among the remaining 56 patients, there were 49 men and 7 women with average age of $52.5 \pm 12.6$ years old. Among SCI patients who consented to DITI study, 29 patients with neurological injury level at T6 or above and 27 with injury level at $\mathrm{T} 7$ or below participated in this study according to the International Standards for Neurological Classification of Spinal Cord Injury classification. The control group consisted of 20 healthy adults.

\section{Method}

\section{Measuring core temperature}

Oral thermometers are widely used to measure core temperature. In this study, an oral thermometer was placed under the tongue for approximately 5 minutes for measurement. Measurements were taken twice so that the median value could be used.

\section{Measuring body surface temperature}

DITI (Iris-XP; Medicore Co. Ltd., Seoul, Korea) was used to measure body surface temperature. The DITI device consists of an infrared camera, a computer, and an LCD monitor. The infrared camera lens measures infrared radiation that is emitted from the body's surface to show temperature differences by color. The temperature of the infrared thermographic imaging room was maintained at $19^{\circ} \mathrm{C}-20^{\circ} \mathrm{C}$, and the humidity was approximately $60 \%$. Light and heat were blocked and indoor airflow was maintained constantly. Before the thermographic imaging was measured, the standard guideline of the American Academy of Thermology that was announced in 1987 was followed [14]. Patients were asked to stop taking medications that could have affected the autonomic 
nervous system at least 3 days prior to examination. One day before examination, patients were also asked to refrain from physical therapy, thermotherapy, and electrophysiologic study. To exclude the effect of the circadian rhythm of body temperature, measurements were taken between $8 \mathrm{AM}$ and $9 \mathrm{AM}$ in a fasting state. Subjects were undressed and acclimated to the examination room temperature for 20 minutes. Then, DITI was taken at approximately $1.5 \mathrm{~m}$ away from the camera. Body surface temperature was measured at the anterior thigh, anterior tibia and lower abdomen. Average value was used after 4 measurements were taken by a single examiner, and median value was used after both sides were measured.

\section{Statistical analysis}

SPSS ver. 18.0 for Windows (SPSS Inc., Chicago, IL, USA) was used for the statistical analysis. One-way analysis of variance (ANOVA) was used to compare BMI and age among the 3 groups. The Kruskal-Wallis test was used to compare the anterior thigh, anterior tibia, and lower abdomen temperatures in each of the 3 groups. Then, for the post hoc test, the Mann-Whitney test with Bonferroni correction was used to test for statistical significance.
To compare differences between the SCI group at $\mathrm{T} 6$ or above and the group at T7 or below by injury severity and injury duration, the Mann-Whitney test was used for statistical significance, and significance was set at below 0.05. With the Mann-Whitney test with Bonferroni correction, $\mathrm{p}$-value was set below 0.017 .

\section{RESULTS}

\section{Demographic data}

Among the 29 SCI patients who were at $\mathrm{T} 6$ or above, average age was $54.9 \pm 10.0$ years and average injury duration was 283 days. The number of acute SCI patients of less than 7 months' duration was 16 , and that of chronic patients of more than 6 months was 13. Among the 27 SCI patients who were at T7 or below, average age was $50.5 \pm 12.0$ years and average injury duration was 354 days. The number of acute SCI patients of less than 7 months' duration was 17 , and that of chronic patients of more than 6 months was 10 . Among the 20 healthy adults in the control group, average age was $48.1 \pm 4.8$ years. Among the SCI patients at T6 or above, all 29 patients had cervical injuries; thoracic injury patients were not recruited.

Table 1. Demographic and clinical characteristics

\begin{tabular}{|c|c|c|c|c|}
\hline & $\begin{array}{c}\text { Upper SCI } \\
(n=29)\end{array}$ & $\begin{array}{c}\text { Lower SCI } \\
(\mathbf{n}=27)\end{array}$ & $\begin{array}{c}\text { Control group } \\
(\mathbf{n}=\mathbf{2 0})\end{array}$ & p-value \\
\hline Gender (male:female) & $25: 4$ & $24: 3$ & $17: 3$ & 1.000 \\
\hline Age & $54.9 \pm 10.0$ & $50.5 \pm 12.0$ & $48.1 \pm 4.8$ & 0.251 \\
\hline \multicolumn{5}{|l|}{ Injury level } \\
\hline Cervical & 29 & 0 & - & - \\
\hline Thoracic & 0 & 21 & - & - \\
\hline Lumbar & 0 & 6 & - & - \\
\hline \multicolumn{5}{|l|}{ AIS } \\
\hline A & 0 & 0 & - & - \\
\hline B & 2 & 2 & - & - \\
\hline $\mathrm{C}$ & 3 & 4 & - & - \\
\hline $\mathrm{D}$ & 24 & 21 & - & - \\
\hline $\mathrm{BMI}\left(\mathrm{kg} / \mathrm{m}^{2}\right)$ & $23.0 \pm 0.9$ & $23.1 \pm 0.7$ & $22.8 \pm 0.6$ & 0.563 \\
\hline \multicolumn{5}{|l|}{ Phase } \\
\hline Acute & 16 & 17 & - & - \\
\hline Chronic & 13 & 10 & - & - \\
\hline Duration (day) & $283 \pm 147$ & $354 \pm 134$ & - & - \\
\hline
\end{tabular}

Values are presented as number or mean \pm standard deviation.

SCI, spinal cord injury; Upper SCI, neurological injury level is T6 or above; Lower SCI, neurological injury level is T7 or below; AIS, American Spinal Injury Association impairment scale; BMI, body mass index. 
Among the SCI patients at T7 or below, there were 21 thoracic injury patients and 6 lumbar injury patients. There were no statistically significant differences among the 3 groups in terms of age or BMI (Table 1).

\section{Body surface temperature distribution by group}

Core temperature and body surface temperature were compared among the healthy adults, the SCI patients at T6 or above and the SCI patients at T7 or below (Table 2). The measurement results for the healthy adults were as follows: core temperature $36.6^{\circ} \mathrm{C} \pm 0.2^{\circ} \mathrm{C}$; body surface temperature of anterior thigh $30.0^{\circ} \mathrm{C} \pm 0.5^{\circ} \mathrm{C}$; body surface temperature of anterior tibia $30.0^{\circ} \mathrm{C} \pm 0.6^{\circ} \mathrm{C}$; and body surface temperature of anterior lower abdomen $29.9^{\circ} \mathrm{C} \pm 0.4^{\circ} \mathrm{C}$. The differences between maximum and minimum temperature at each area were $0.21^{\circ} \mathrm{C} \pm 0.17^{\circ} \mathrm{C}$ at anterior thigh, $0.21^{\circ} \mathrm{C} \pm 0.15^{\circ} \mathrm{C}$ at anterior tibia, and $0.24^{\circ} \mathrm{C} \pm 0.13^{\circ} \mathrm{C}$ at lower abdomen. The measurement results for the SCI patients at $\mathrm{T} 6$ or above were as follows: core temperature $36.4^{\circ} \mathrm{C} \pm 0.2^{\circ} \mathrm{C}$; body surface temperature of anterior thigh $28.8^{\circ} \mathrm{C} \pm 0.9^{\circ} \mathrm{C}$; body surface temperature of anterior tibia $28.5^{\circ} \mathrm{C} \pm 0.9^{\circ} \mathrm{C}$; and body surface temperature of lower abdomen $28.5^{\circ} \mathrm{C} \pm 0.7^{\circ} \mathrm{C}$. The differences between maximum and minimum temperature at each area were $0.21^{\circ} \mathrm{C} \pm 0.11^{\circ} \mathrm{C}$ at anterior thigh, $0.26^{\circ} \mathrm{C} \pm 0.15^{\circ} \mathrm{C}$ at anterior tibia, and $0.20^{\circ} \mathrm{C} \pm 0.16^{\circ} \mathrm{C}$ at lower abdomen. The measurement results for the SCI patients at $\mathrm{T} 7$ or below were as follows: core temperature $36.5^{\circ} \mathrm{C} \pm 0.4^{\circ} \mathrm{C}$; body surface temperature of anterior thigh $29.8^{\circ} \mathrm{C} \pm 0.9^{\circ} \mathrm{C}$; body surface temperature of ante- rior tibia $29.7^{\circ} \mathrm{C} \pm 0.7^{\circ} \mathrm{C}$; and body surface temperature of lower abdomen $29.6^{\circ} \mathrm{C} \pm 0.6^{\circ} \mathrm{C}$. The differences between maximum and minimum temperature at each area were $0.23^{\circ} \mathrm{C} \pm 0.13^{\circ} \mathrm{C}$ at anterior thigh, $0.25^{\circ} \mathrm{C} \pm 0.16^{\circ} \mathrm{C}$ at anterior tibia, and $0.21^{\circ} \mathrm{C} \pm 0.16^{\circ} \mathrm{C}$ at lower abdomen. There were no statistically significant differences in the comparisons of core temperature among the 3 groups.

Comparing body surface temperatures at the anterior thigh, there was a difference of $1.2^{\circ} \mathrm{C}$ on average between the healthy adults and the SCI patients at $\mathrm{T} 6$ or above, a statistically significant difference $(\mathrm{p}<0.017)$. There was a difference of $0.2^{\circ} \mathrm{C}$ on average between the healthy adults and the SCI patients at T7 or below, which was not statistically significant. There was a difference of $1.0^{\circ} \mathrm{C}$ on average between the SCI patients at T6 or above and those at $\mathrm{T} 7$ or below, which was statistically significant $(\mathrm{p}<0.017)$.

Comparing body surface temperatures at the anterior tibia, there was a difference of $1.5^{\circ} \mathrm{C}$ on average between the healthy adults and the SCI patients at $\mathrm{T} 6$ or above, which was statistically significant $(\mathrm{p}<0.017)$. There was a difference of $0.3^{\circ} \mathrm{C}$ on average between the healthy adults and the SCI patients at T7 or below, which was not statistically significant. There was a difference of $1.3^{\circ} \mathrm{C}$ on average between the SCI patients at T6 or above and those at T7 or below, which was statistically significant $(\mathrm{p}<0.017)$.

Comparing body surface temperatures at the lower abdomen, there was a difference of $1.4^{\circ} \mathrm{C}$ on average between the healthy adults and the SCI patients at $\mathrm{T} 6$ or above, which was statistically significant $(\mathrm{p}<0.017)$. There was a difference of $0.3^{\circ} \mathrm{C}$ on average between the healthy

Table 2. Comparison of body core temperature and skin temperature among the three groups

\begin{tabular}{|c|c|c|c|c|c|c|c|}
\hline \multirow[b]{2}{*}{$\begin{array}{c}\text { Temperature } \\
\left({ }^{\circ} \mathrm{C}\right)\end{array}$} & \multirow[b]{2}{*}{$\begin{array}{c}\text { Upper SCI } \\
(\mathbf{n}=29)\end{array}$} & \multirow[b]{2}{*}{$\begin{array}{c}\text { Lower SCI } \\
(\mathbf{n}=27)\end{array}$} & \multirow[b]{2}{*}{$\begin{array}{l}\text { Control } \\
\text { group } \\
(\mathbf{n}=\mathbf{2 0})\end{array}$} & \multicolumn{4}{|c|}{ p-value } \\
\hline & & & & $\begin{array}{c}\text { Upper SCI \& } \\
\text { lower SCI \& } \\
\text { control group }\end{array}$ & $\begin{array}{c}\text { Upper SCI \& } \\
\text { lower SCI }\end{array}$ & $\begin{array}{c}\text { Lower SCI \& } \\
\text { control group }\end{array}$ & $\begin{array}{c}\text { Upper SCI \& } \\
\text { control group }\end{array}$ \\
\hline Body core & $36.4 \pm 0.2$ & $36.5 \pm 0.4$ & $36.6 \pm 0.2$ & 0.417 & 0.966 & 0.988 & 0.933 \\
\hline Anterior thigh & $28.8 \pm 0.9$ & $29.8 \pm 0.9$ & $30.0 \pm 0.5$ & $0.000^{*}$ & $0.001^{a)}$ & 0.752 & $0.001^{b)}$ \\
\hline
\end{tabular}

SCI, spinal cord injury; Upper SCI, neurological injury level is T6 or above; Lower SCI, neurological injury level is T7 or below.

${ }^{a)}$ Statistically significant $(\mathrm{p}<0.017)$ difference between upper SCI and lower SCI by Mann-Whitney test with Bonferroni correction.

${ }^{\mathrm{b}}$ Statistically significant $(\mathrm{p}<0.017)$ differences between upper SCI and control group by Mann-Whitney test with Bonferroni correction.

${ }^{*} \mathrm{p}<0.05$ by Kruskal-Wallis test. 
adults and the SCI patients at T7 or below, which was not statistically significant. There was a difference of $1.1^{\circ} \mathrm{C}$ on average between the SCI patients at $\mathrm{T} 6$ or above and those at T7 or below, which was statistically significant $(\mathrm{p}<0.017)$.

In the SCI T6 and SCI T7 patients, core temperature and body surface temperature were compared between the acute SCI patients of less than 7 months and the chronic SCI patients of more than 6 months (Table 3). The differences were not significant in the core and body surface temperatures of the anterior thigh, anterior tibia, and lower abdomen.

In the SCI patients at $\mathrm{T} 6$ or above and those at $\mathrm{T} 7$ or below, core and surface temperatures were compared between American Spinal Injury Association impairment scale (AIS) B and C and AIS D patients (Table 4). The measurement results for AIS B and C patients among the SCI patients at $\mathrm{T} 6$ or above were as follows: core temperature $36.5^{\circ} \mathrm{C} \pm 0.2^{\circ} \mathrm{C}$; body surface temperature of anterior thigh $28.2^{\circ} \mathrm{C} \pm 1.1^{\circ} \mathrm{C}$; body surface temperature of anterior tibia $28.0^{\circ} \mathrm{C} \pm 0.6^{\circ} \mathrm{C}$; and body surface temperature of lower ab- domen $27.8^{\circ} \mathrm{C} \pm 0.6^{\circ} \mathrm{C}$. The corresponding measurement results in the AIS D group were as follows: core temperature $36.4^{\circ} \mathrm{C} \pm 0.3^{\circ} \mathrm{C}$; body surface temperature of anterior thigh $28.9^{\circ} \mathrm{C} \pm 0.8^{\circ} \mathrm{C}$; body surface temperature of anterior tibia $28.8^{\circ} \mathrm{C} \pm 0.8^{\circ} \mathrm{C}$; and body surface temperature of lower abdomen $28.7^{\circ} \mathrm{C} \pm 0.9^{\circ} \mathrm{C}$. The results showed that the body surface temperatures of the anterior thigh, anterior tibia, and lower abdomen were approximately $0.8^{\circ} \mathrm{C}$ higher in the AIS D group, a statistically significant difference $(\mathrm{p}<0.05)$. The measurement results for the AIS B and C group among SCI patients at T7 or below were as follows: core temperature $36.5^{\circ} \mathrm{C} \pm 0.2^{\circ} \mathrm{C}$; body surface temperature of anterior thigh $29.0^{\circ} \mathrm{C} \pm 0.8^{\circ} \mathrm{C}$; body surface temperature of anterior tibia $29.2^{\circ} \mathrm{C} \pm 0.7^{\circ} \mathrm{C}$; and body surface temperature of lower abdomen $29.3^{\circ} \mathrm{C} \pm 0.5^{\circ} \mathrm{C}$. The corresponding measurement results in the AIS D group was as follows: core temperature $36.5^{\circ} \mathrm{C} \pm 0.2^{\circ} \mathrm{C}$; body surface temperature of anterior thigh $29.7^{\circ} \mathrm{C} \pm 0.9^{\circ} \mathrm{C}$; body surface temperature of anterior tibia $29.8^{\circ} \mathrm{C} \pm 0.6^{\circ} \mathrm{C}$; and body surface temperature of lower abdomen $29.9^{\circ} \mathrm{C} \pm 0.6^{\circ} \mathrm{C}$. Between the two groups, the body surface temperatures of

Table 3. Comparison of body core temperature and skin temperature between acute phase and chronic phase SCI

\begin{tabular}{|c|c|c|c|c|c|c|}
\hline \multirow[b]{2}{*}{ Temperature $\left({ }^{\circ} \mathrm{C}\right)$} & \multicolumn{3}{|c|}{ Upper SCI } & \multicolumn{3}{|c|}{ Lower SCI } \\
\hline & $\begin{array}{l}\text { Acute phase } \\
(n=16)\end{array}$ & $\begin{array}{c}\text { Chronic phase } \\
(n=13)\end{array}$ & p-value & $\begin{array}{c}\text { Acute phase } \\
(n=17)\end{array}$ & $\begin{array}{c}\text { Chronic phase } \\
\quad(n=10)\end{array}$ & p-value \\
\hline Body core & $36.5 \pm 0.2$ & $36.4 \pm 0.3$ & 0.430 & $36.5 \pm 0.2$ & $36.5 \pm 0.2$ & 0.840 \\
\hline Anterior thigh & $28.6 \pm 0.8$ & $29.0 \pm 0.9$ & 0.280 & $29.7 \pm 1.0$ & $29.9 \pm 1.0$ & 0.600 \\
\hline Anterior tibia & $28.7 \pm 0.9$ & $28.4 \pm 0.7$ & 0.375 & $29.6 \pm 0.6$ & $29.8 \pm 0.7$ & 0.206 \\
\hline Lower abdomen & $28.5 \pm 0.8$ & $28.6 \pm 0.7$ & 0.720 & $29.6 \pm 0.7$ & $29.6 \pm 0.5$ & 0.657 \\
\hline
\end{tabular}

Values are presented as mean \pm standard deviation.

SCI, spinal cord injury; Upper SCI, neurological injury level is T6 or above; Lower SCI, neurological injury level is T7 or below.

Table 4. Comparison of body core temperature and skin temperature between AIS B and C and AIS D in SCI

\begin{tabular}{|c|c|c|c|c|c|c|}
\hline \multirow{2}{*}{ Temperature $\left({ }^{\circ} \mathrm{C}\right)$} & \multicolumn{3}{|c|}{ Upper SCI } & \multicolumn{3}{|c|}{ Lower SCI } \\
\hline & AIS B, C $(n=5)$ & AIS D $(n=24)$ & p-value & AIS B, C (n=6) & AIS D $(n=21)$ & p-value \\
\hline Body core & $36.5 \pm 0.2$ & $36.4 \pm 0.3$ & 0.240 & $36.5 \pm 0.2$ & $36.5 \pm 0.2$ & 0.750 \\
\hline Anterior thigh & $28.2 \pm 1.1$ & $28.9 \pm 0.8$ & $0.041^{\text {a) }}$ & $29.0 \pm 0.8$ & $29.7 \pm 0.9$ & $0.036^{\mathrm{b})}$ \\
\hline Anterior tibia & $28.0 \pm 0.6$ & $28.8 \pm 0.8$ & $0.033^{\mathrm{a})}$ & $29.2 \pm 0.7$ & $29.8 \pm 0.6$ & $0.040^{\mathrm{b})}$ \\
\hline Lower abdomen & $27.8 \pm 0.6$ & $28.7 \pm 0.9$ & $0.010^{\mathrm{a})}$ & $29.3 \pm 0.5$ & $29.9 \pm 0.6$ & $0.021^{\mathrm{b})}$ \\
\hline
\end{tabular}

Values are presented as mean \pm standard deviation.

SCI, spinal cord injury; Upper SCI, neurological injury level is T6 or above; Lower SCI, neurological injury level is T7 or below; AIS, American Spinal Injury Association impairment scale.

${ }^{a}$ Statistically significant $(\mathrm{p}<0.05)$ difference between AIS B, C and AIS D in upper SCI by Mann-Whitney test.

${ }^{b)}$ Statistically significant $(p<0.05)$ difference between AIS B, C and AIS D in lower SCI by Mann-Whitney test. 
the anterior thigh, anterior tibia, and lower abdomen approximately $0.6^{\circ} \mathrm{C}$ higher in the AIS D group, a statistically significant difference $(\mathrm{p}<0.05)$.

\section{DISCUSSION}

The human body's temperature is maintained constantly by a sophisticated thermoregulatory center in the hypothalamus. Heat and cold signals are carried by the afferent nerve to the hypothalamus, which then integrates this information to regulate thermogenesis by activating or inhibiting the sympathetic nervous system [15]. Thermal regulation is impaired in patients with SCI. As a result, they cannot appropriately respond to the changing temperatures of their surrounding environments. This phenomenon is called poikilothermia [13]. Constant exposure to low or high temperatures can cause bleeding, metabolic acidosis, arrhythmia, decline in cardiac contractility, and exercise-induced hyperthermia [10,16-21]. It was reported in preceding studies that this phenomenon could happen frequently among patients with SCI, especially in those with complete lesion at $\mathrm{T} 6$ or above [13]. This is attributable to the loss of supraspinal control regulated by the hypothalamus and to damage to the afferent and efferent pathways of the sympathetic nervous system. All of these lead to dysregulation in vasomotor tone, skeletal muscle shivering and sweating dysfunction [22].

Skin plays an important role in regulating body temperature as a dynamic membrane that regulates interactions between surrounding environments and the human body [23]. Body surface temperature is affected by diverse factors but is mainly regulated by the sympathetic nervous system. It is known that there is a complex interaction among core temperature, body surface blood flow, physical conditions of the surrounding environment, skin fat and dermal thickness, internal heat conduction and convection, and body temperature circadian rhythm [2,3,24]. To measure body surface temperature, contact thermography and DITI can be used. DITI is being used widely because it is convenient and can measure changing body temperatures as accurately as contact thermography [2527]. Chun et al. [28] reported that absolute temperature measured through DITI had low diagnostic efficacy because of fluctuation. However, in the study of Chun et al. [28], the severe temperature changes and low diagnostic efficacy are assumed to have happened because physical conditions such as the study subjects' circadian rhythms and BMIs were not considered. In this study, to exclude factors that might have affected body surface temperature changes, examinations were conducted between 8 AM and $9 \mathrm{AM}$, and physical environmental conditions were maintained constantly. In particular, to exclude internal factors, BMI was considered in selecting the SCI patient group and the healthy adults. In this study, the differences between each individual's minimum and maximum temperature were found to be more stable than were the findings from other studies including that of Chun et al. [28].

Downey et al. [4] confirmed the existence of central thermoreceptors and peripheral cold receptors in the skin surface regarding body temperature regulation. With SCI patients at $\mathrm{T} 6$ or above, body temperature is mainly regulated by central thermoreceptors. Meanwhile, in SCI patients at $\mathrm{T} 7$ or below, both core temperature and body surface temperature receptors have an effect. It has been reported that this caused more severe dysfunction in body temperature regulation against external temperature change among SCI patients at T6 or above. In this study, SCI patients at both $\mathrm{T} 6$ or above and $\mathrm{T} 7$ or below were exposed to an environment of approximately $20^{\circ} \mathrm{C}$. In the process, this study referred to preceding studies that used DITI to investigate both healthy people and SCI patients $[11,28]$. We observed core temperature decline among healthy adults, SCI patients at T6 or above or SCI patients at $\mathrm{T} 7$ or below. However, body surface temperature in SCI patients at $\mathrm{T} 6$ or above was lower than that in SCI patients at T7 or below and in healthy adults. This confirmed that dysfunction in body surface temperature regulation was more severe among SCI patients at $\mathrm{T} 6$ or above, which was similar to the results in Downey et al. [4].

It is known that more severe SCI causes more severe dysfunction in body temperature regulation [13]. Accordingly, this study compared core and body surface temperatures based on the severity of SCI. Because of the limited number of recruited subjects, this study compared AIS B and C patients with AIS D patients (Table 4). Among SCI patients at $\mathrm{T} 6$ or above and those at $\mathrm{T} 7$ or below, core temperature did not show a significant difference between AIS B and C patients and AIS D patients. However, in terms of body surface temperature, a signifi- 
cant difference was observed between the AIS B and C and AIS D groups $(p<0.05)$. This confirmed body surface temperature regulation dysfunction among AIS B and C patients compared with AIS D patients with relatively low degree of injury among incomplete SCI patients.

Some previous studies have investigated changes in core and body surface temperatures among SCI patients. Khan et al. [7] studied hypothermia frequency by measuring body temperature in 50 patients who had experienced their SCIs more than 5 years prior to the study. Body temperature was measured 867 times, and roughly $63 \%$ of participants showed subnormal temperatures $\left(35^{\circ} \mathrm{C}-36.5^{\circ} \mathrm{C}\right)$; roughly $3 \%$ showed hypothermia $\left(<35^{\circ} \mathrm{C}\right)$. In the present study, body temperature was measured 26 times among 13 chronic SCI patients who were at T6 or above. The results showed that $57 \%$ demonstrated subnormal temperatures and that hypothermia was not observed. In the study by Khan et al. [7], most of the 50 patients corresponded to AIS grade A and the study subjects were in the chronic phase of their injuries, that is, SCI of more than 5 years' duration. In this study, most of the cervical injury patients corresponded to AIS grade D, and the average injury duration among SCI patients at T6 or above was $283 \pm 147$ days, which was shorter and presumably led to different study results.

Claus-Walker et al. [12] reported that cold stimuli among complete SCI patients could cause hypothermia. It has also been reported that the longer the duration of SCI, the more body temperature regulation function could decline. Studies reported that most functions were recovered in the first 6 months after SCI $[29,30]$. In this study, we measured core body temperature and body surface temperature in incomplete SCI patients to compare thermal regulation function by injury duration. SCI patients at $\mathrm{T} 6$ or above and those at $\mathrm{T} 7$ or below were divided into acute and chronic patients, with the cut-off at 6 months. There were no significant temperature differences by injury duration in any group in core or body surface temperature at the lower abdomen, anterior thigh, or anterior tibia. Body temperature regulation was maintained relatively constantly regardless of injury duration among incomplete SCI patients compared with complete SCI patients. Claus-walker et al. [12] studied complete SCI patients, and average injury duration among them was $101 \pm 45$ months. However, we studied incomplete SCI patients, and the average injury duration of chronic SCI patients was $43.8 \pm 40.0$ months, which presumably is the reason for the different study results from those of Clauswalker.

Another factor that might affect body surface temperature is pain. No correlation between pain and body surface temperature changes has been clearly identified yet [31]. However, many preceding reports have described some relationship between skin temperature changes by DITI and pain from radiculopathy or nerve entrapment syndrome [32-35]. In particular, body temperature change according to central pain is still controversial in many studies $[9,11,36]$. Park et al. [11], on central pain after SCI, reported that the complete SCI patient group with central pain showed significantly lower body surface temperatures as measured through DITI than did the patient group without central pain. Sherman et al. [9] reported that body surface temperature dropped at the skin level below the cord injury and that body surface temperature was higher in the area with central pain. In this study, 26 out of 29 SCI patients at T6 or above complained of central pain and 25 out of 27 SCI patients at T7 or below did so. Because most patients complained of central pain, it was impossible to conduct statistical verification of body surface temperature based on the presence of central pain. In the future, more advanced studies need to be carried out by recruiting patient groups based on the presence of central pain.

With regard to the limitations of this study, the patient group of T6 or above were all cervical injury patients because thoracic injury patients were not recruited. Among the lower cord injury patients, thoracic cord injuries outnumbered lumbar injuries, which made it impossible to conduct a comparative analysis by level of injury. Body surface temperature was measured only at the lower limbs and lower abdomen, not at the posterior surfaces of the lower limbs. Separately, the recruited women's menstrual cycles were not considered. However, because women accounted for less than $15 \%$ in each group, menstrual cycle are assumed to have had little effect. Another limitation is that no comparative analysis was conducted based on the presence of central pain because most patients complained of central pain. In the future, these limitations need to be considered in order to conduct more studies on core temperature and body surface temperature in spinal cord injury patients.

In SCI patients and healthy adults, core temperature 
was measured along with body surface temperature at the anterior thigh, anterior tibia, and lower abdomen using DITI. The aim was to confirm dysfunction in body surface temperature regulation among incomplete SCI patients. The body surface temperature regulation dysfunction was especially severe among SCI patients at T6 or above compared with patients at $\mathrm{T} 7$ or below. It was also confirmed that the more severe the cord injury, the greater the dysfunction in body surface temperature regulation. Because this study enrolled incomplete SCI patients, declining core temperature was not observed compared with preceding studies on complete SCI patients. However, we observed that body surface temperature in SCI patients was lower than that among healthy adults. Body surface temperature declined significantly, especially among patients at SCI T6 or above compared with healthy adults and the SCI patient group at T7 or below.

\section{CONFLICT OF INTEREST}

No potential conflict of interest relevant to this article was reported.

\section{REFERENCES}

1. Krassioukov AV, Karlsson AK, Wecht JM, Wuermser LA, Mathias CJ, Marino RJ, et al. Assessment of autonomic dysfunction following spinal cord injury: rationale for additions to International Standards for Neurological Assessment. J Rehabil Res Dev 2007;44:103-12.

2. Uematsu S, Edwin DH, Jankel WR, Kozikowski J, Trattner M. Quantification of thermal asymmetry. Part 1: Normal values and reproducibility. J Neurosurg 1988; 69:552-5.

3. Edeiken J, Shaber G. Thermography: a reevaluation. Skeletal Radiol 1986;15:545-8.

4. Downey JA, Miller JM, Darling RC. Thermoregulatory responses to deep and superficial cooling in spinal man. J Appl Physiol 1969;27:209-12.

5. Feldman F. Thermography of the hand and wrist: practical applications. Hand Clin 1991;7:99-112.

6. Feldman F, Nickoloff EL. Normal thermographic standards for the cervical spine and upper extremities. Skeletal Radiol 1984;12:235-49.

7. Khan S, Plummer M, Martinez-Arizala A, Banovac K. Hy- pothermia in patients with chronic spinal cord injury. J Spinal Cord Med 2007;30:27-30.

8. Roehl K, Becker S, Fuhrmeister C, Teuscher N, Futing M, Heilmann A. New, non-invasive thermographic examination of body surface temperature on tetraplegic and paraplegic patients, as a supplement to existing diagnostic measures. Spinal Cord 2009;47:492-5.

9. Sherman RA, Ernst JL, Markowski J. Relationships between near surface blood flow and altered sensations among spinal cord injured veterans. Am J Phys Med 1986;65:281-97.

10. Price MJ, Campbell IG. Effects of spinal cord lesion level upon thermoregulation during exercise in the heat. Med Sci Sports Exerc 2003;35:1100-7.

11. Park CI, Park ES, Kim YC, Lim KB, Yi CH. Digital infrared thermal imaging on patients with complete spinal cord injuries and central pain. J Korean Acad Rehabil Med 1996;20:436-41.

12. Claus-Walker J, Halstead LS, Carter RE, Campos RJ, Spencer WA, Canzoneri J 3rd. Physiological responses to cold stress in healthy subjects and in subjects with cervical cord injuries. Arch Phys Med Rehabil 1974;55: 485-90.

13. Bryce TN, Ragnarsson KT, Stein AB, Biering-Sorensen F. Spinal cord injury. In: Braddom RL, editor. Physical medicine and rehabilitation. 4th ed. Philadelphia: Saunders; 2011. p. 1293-1345.

14. American Medical Association, Council on Scientific Affairs. Thermography in neurological and musculoskeletal conditions. Thermology 1987;2:600-7.

15. Boulant JA. Thermoregulation. In: Mackowiak PA, editor. Fever: basic mechanisms and management. 2nd ed. Philadelphia: Lippincott Williams \& Wilkins; 1997. p. 35-58.

16. Jurkovich GJ, Greiser WB, Luterman A, Curreri PW. Hypothermia in trauma victims: an ominous predictor of survival. J Trauma 1987;27:1019-24.

17. Luna GK, Maier RV, Pavlin EG, Anardi D, Copass MK, Oreskovich MR. Incidence and effect of hypothermia in seriously injured patients. J Trauma 1987;27:1014-8.

18. Tsuei BJ, Kearney PA. Hypothermia in the trauma patient. Injury 2004;35:7-15.

19. Cosgriff N, Moore EE, Sauaia A, Kenny-Moynihan M, Burch JM, Galloway B. Predicting life-threatening coagulopathy in the massively transfused trauma patient: hypothermia and acidoses revisited. J Trauma 1997;42:857- 
62.

20. Greene PS, Cameron DE, Mohlala ML, Dinatale JM, Gardner TJ. Systolic and diastolic left ventricular dysfunction due to mild hypothermia. Circulation 1989; 80(5 Pt 2):III44-8.

21. Wright V, Johns RJ. Quantitative and qualitative analysis of joint stiffness in normal subjects and in patients with connective tissue diseases. Ann Rheum Dis 1961;20:36-46.

22. Cesario TC, Darouiche RO. Thermoregulation in the SCI patient. In: Lin VW, editor. Spinal cord medicine: principles and practice. New York: Demos Medical Publishing; 2003. p. 209-11.

23. Ring F. Thermal imaging today and its relevance to diabetes. J Diabetes Sci Technol 2010;4:857-62.

24. Krauchi K, Wirz-Justice A. Circadian rhythm of heat production, heart rate, and skin and core temperature under unmasking conditions in men. Am J Physiol 1994;267(3 Pt 2):R819-29.

25. Matsukawa T, Ozaki M, Nishiyama T, Imamura M, Kumazawa T. Comparison of infrared thermometer with thermocouple for monitoring skin temperature. Crit Care Med 2000;28:532-6.

26. Hershler C, Conine TA, Nunn A, Hannay M. Assessment of an infra-red non-contact sensor for routine skin temperature monitoring: a preliminary study. J Med Eng Technol 1992;16:117-22.

27. Buono MJ, Jechort A, Marques R, Smith C, Welch J. Comparison of infrared versus contact thermometry for measuring skin temperature during exercise in the heat. Physiol Meas 2007;28:855-9.

28. Chun SI, Park ES, Yi CH. Digital infrared thermal imaging on normal healthy subjects. J Korean Acad Rehabil Med 1995;19:425-30.

29. Tominaga S. Periodical, neurological-functional assessment for cervical cord injury. Paraplegia 1989;27:22736.

30. Folman Y, el Masri W. Spinal cord injury: prognostic indicators. Injury 1989;20:92-3.

31. Besson M, Brook P, Chizh BA, Pickering AE. Tactile allodynia in patients with postherpetic neuralgia: lack of change in skin blood flow upon dynamic stimulation. Pain 2005;117:154-61.

32. So YT, Olney RK, Aminoff MJ. A comparison of thermography and electromyography in the diagnosis of cervical radiculopathy. Muscle Nerve 1990;13:1032-6.

33. So YT, Aminoff MJ, Olney RK. The role of thermography in the evaluation of lumbosacral radiculopathy. Neurology 1989;39:1154-8.

34. Tchou S, Costich JF, Burgess RC, Wexler CE. Thermographic observations in unilateral carpal tunnel syndrome: report of 61 cases. J Hand Surg Am 1992;17:631-7.

35. Jang YY, Byun SH, Lee SJ, Kim TU, Hyun JK. Clinical significance of digital infrared thermal imaging in unilateral ulnar neuropathy. J Korean EMG Electrodiagn Med 2009;11:78-84.

36. Balazy TE. Clinical management of chronic pain in spinal cord injury. Clin J Pain 1992;8:102-10. 